formulating this project, and Dr J Milledge (Northwick Park Hospital, London) for advice on the manuscript.

Funding: Material support provided by Psion UK (Psion 3a palmtop computer), DeVilbiss UK (pulse oximeter), Norton Pharmaceuticals (temazepam tablets), and Advisory Services (placebo tablets).

Conflict of interest: None.

1 Barcroft J. The respiratory function of the blood, part 2. Lessons from high altitude. Cambridge: Cambridge University Press, 1925.

Ravenhill TH. Some experiences of mountain sickness in the Andes. $J$ Trop Med Hyg 1913;16:313-20.

3 Anholm JD, Powles AC, Downey R, Houston CS, Sutton JR, Bonnet MH, et al. Operation Everest. II. Arterial oxygen saturation during sleep at extreme altitude. Am Rev Respir Dis 1992;145:817-26.

4 Weil JV. Sleep at high altitude. Clin Chest Med 1985;6:615-21.

5 Reite M, Jackson D, Cahoon RL, Weil JV. Sleep physiology at high altitude. Electroencephalogr Clin Neuophysiol 1975;38:463-71.

6 West JB, Peters RM, Aksnes G, Marek KH, Mill JS, Shoene RB. Nocturnal periodic breathing at altitudes of $6300 \mathrm{~m}$ and $8050 \mathrm{~m}$. J Appl Physiol $1986: 61: 280-7$
7 Goldenberg F, Richalet JP, Onnen I, Antezana AM. Sleep apneas and high altitude newcomers. Int J Sports Med 1992;13:S34-6.

8 Bonnet MH, Dexter JR, Arand DL. The effect of triazolam on arousal and respiration in central sleep apnoea patients. Sleep 1990;13:31-41.

9 Bonnet MH. Performance and sleepiness following moderate sleep disruption and slow wave sleep deprivation. Physiol Behav 1986;37:915-8.

10 Nicholson AN, Smith PA, Stone BM, Bradwell AR, Coote JH. Altitude insomnia: studies during an expedition to the Himalaya. Sleep 1988;11:354-61.

11 Laserre E. Insomnies d'altitude: efficacité du fluritrazepam. [High altitude insomnia: efficacy of fluritrazepam.] Nouv Presse Med 1979;8:2577-8.

12 Goldenberg F, Richalet JP, Jouhandin M, Gisquet A, Keromes A, Larmignat P. Respiration periodique pendant le sommeil en altitude. Effets d'une benzodiazepine hypnotique, le loprazolam. [Periodic respiration during sleep at high altitude. Effect of a benzodiazepine hypnotic, loprazolam.] Presse Med 1988;17:471-4.

13 Sutton JR, Gray GW, Houston CS, Powles ACP. Effects of acclimatization on sleep hypoxaemia at altitude. In: West JB, Lahiri S, eds. High altitude and man. Washington, DC: American Physiological Society, 1983.

14 Powles SCP, Sutton JR. Sleep at Altitude. Semin Resp Med 1983;5:175-80.

(Accepted 28 October 1997)

\title{
Case-control study of risk of cerebral sinus thrombosis in oral contraceptive users who are carriers of hereditary prothrombotic conditions
}

\author{
S F T M de Bruijn, J Stam, M M W Koopman, J P Vandenbroucke for the Cerebral Venous Sinus \\ Thrombosis Study Group
}

\begin{abstract}
Objective: To investigate whether users of oral contraceptives who are carriers of a hereditary prothrombotic condition (factor V Leiden mutation, protein $\mathrm{C}, \mathrm{S}$, or antithrombin deficiency) have an increased risk of cerebral sinus thrombosis.

Design: Comparison of a prospective series of cases of cerebral sinus thrombosis with population data. Setting: Neurological teaching hospitals from different regions in the Netherlands (cases) and a representative sample of the non-institutionalised Dutch population (controls).

Subjects: 40 women aged $18-54$ years with cerebral sinus thrombosis (cases) and 2248 women aged 18-49 years (controls).

Main outcome measure: Current use of oral contraceptives at the time of the thrombosis (cases) or at the time of the questionnaire (controls). Prevalences of a hereditary prothrombotic condition in patients and in the population with odds ratios.

Results: 34 of 40 (85\%) women with cerebral sinus thrombosis used oral contraceptives, versus 1007 of $2248(45 \%)$ of the control women; the age adjusted odds ratio was 13 (95\% confidence interval 5 to 37$)$. Seven of 36 patients (19\%) had a prothrombotic deficiency, versus $7 \%$ expected in the population; this corresponds to a threefold to fourfold increase in risk. In women who used oral contraceptives and also carried a prothrombotic defect, the odds ratio for cerebral sinus thrombosis was about 30 relative to women who had neither risk factor.
\end{abstract}

Conclusion: The use of oral contraceptives and being a carrier of a hereditary prothrombotic condition increase the risk of and interact in a multiplicative way in the development of cerebral sinus thrombosis.

\section{Introduction}

Epidemiological studies have shown that oral contraceptives carry a small but increased risk of venous thromboembolism (deep vein thrombosis and pulmonary embolism). ${ }^{1}$ Furthermore, women who use oral contraceptives and carry the factor $\mathrm{V}$ Leiden mutation have a higher risk of venous thromboembolism than expected from the mere addition of these risks. ${ }^{2}$ Although the association between oral contraceptives and venous thromboembolism is generally accepted, there remains discussion about possible sources of bias that might influence the magnitude of the risk.

Cerebral venous sinus thrombosis is a relatively rare disease, often with cerebral infarcts, which may lead to seizures, other neurological symptoms, or death. Patients with sinus thrombosis, however, may recover completely." Oral contraceptives and hereditary prothrombotic conditions, such as protein $\mathrm{C}, \mathrm{S}$, and antithrombin deficiency and factor $\mathrm{V}$ Leiden mutation, have been reported as possible causes of cerebral sinus thrombosis. ${ }^{4}$

We compared a series of patients with cerebral venous sinus thrombosis from a prospective treatment trial with population data from the Netherlands to investigate the risk of oral contraceptive use and prothrombotic conditions for cerebral sinus thrombosis.

\section{Patients and methods}

Cases

Cases were patients with cerebral sinus thrombosis (newly diagnosed) who participated in a treatment trial from July 1992 to November 1996 that compared low molecular weight heparin in a therapeutic dose with placebo in a randomised double blind design. Patients
Department of Neurology, Academic Medical Centre, PO Box $22700,1100 \mathrm{DE}$ Amsterdam, Netherlands S F T M de Bruijn, senior registrar in neurology

J Stam, professor of neurology Department of Vascular Medicine, Academic Medical Centre, Amsterdam M M W Koopman, internist

Department of Clinical

Epidemiology,

University hospital, Postbus 9600, 2300 RC Leiden,

Netherlands

J P Vandenbroucke, professor of clinical epidemiology

Correspondence to: Professor Stam j.stam@amc.uva.nl

BMJ 1998;316:589-92 
younger than 18 years and pregnant women were excluded. The trial was conducted in neurological teaching hospitals in different regions in the Netherlands and the United Kingdom. Cerebral sinus thrombosis was confirmed by conventional angiography or magnetic resonance imaging and angiography. For the present analysis we selected all women aged 18-54 from the Dutch part of the trial population who were not in the puerperium (within 30 days post partum).

Information on use of oral contraceptives at the time of the initial symptoms of sinus thrombosis was obtained from the patient or nearest relative and supplemented with hospital discharge letters.

Blood samples were collected and analysed in the participating hospitals. Antithrombin activity and protein $\mathrm{C}$ activity were measured with chromogenic assays. ${ }^{5}$ Protein $\mathrm{C}$ antigen, and total and free protein $\mathrm{S}$ were determined by enzyme linked immunosorbent assay (ELISA) as described elsewhere. ${ }^{6}$ Values were defined as abnormal if they were below the 5 th centiles of the values determined in a group of healthy subjects. Resistance to activated protein $\mathrm{C}$ was assessed by the activated protein $\mathrm{C}$ dependent prolongation of the activated partial thromboplastin time. ${ }^{8}$ An activated protein $\mathrm{C}$ ratio below 2.0 or a normalised ratio lower than 0.80 was considered abnormal. The mutation at position Arg 506 in factor $\mathrm{V}$ was determined with polymerase chain reaction techniques as described previously. ${ }^{9}$

\section{Controls}

The controls comprised a random sample of 2248 women aged 18-49 years from different regions in the Netherlands who were interviewed in 1994 about their current use of contraceptives (continuous health interview survey of the Central Department of Statistics of the Netherlands ${ }^{10}$; the methodology of the questionnaire has been described previously ${ }^{11}$ ).

\section{Statistics}

We calculated odds ratios as approximations of relative risks on the basis of the crude numbers or the percentage distribution; confidence intervals, when appropriate, were calculated by the methods of Woolf or Robins. ${ }^{12}$ When observed odds were compared with estimated population frequencies we omitted the calculation of the confidence intervals.

Use of oral contraceptives and prothrombotic disorders in cases (women with cerebral venous sinus thrombosis aged 18-54 years, puerperium excluded) and use of oral contraceptives in controls

\begin{tabular}{lcccc} 
& \multicolumn{3}{c}{ Cases } & \\
\cline { 2 - 4 } Age (years) & $\begin{array}{c}\text { Proportion } \\
\text { (\%) taking } \\
\text { contraceptives }\end{array}$ & $\begin{array}{c}\text { No with } \\
\text { factor V } \\
\text { Leiden }\end{array}$ & $\begin{array}{c}\text { No with C, S, or } \\
\text { antithrombin } \\
\text { deficiency }\end{array}$ & $\begin{array}{c}\text { Proportion (\%) of } \\
\text { controls taking } \\
\text { contraceptives }\end{array}$ \\
\hline $18-19$ & $3 / 3(100)$ & 1 & 0 & $60 / 107(56)$ \\
\hline $20-24$ & $7 / 7(100)$ & 0 & 0 & $271 / 336(81)$ \\
\hline $25-29$ & $4 / 4(100)$ & 1 & 1 & $255 / 400(64)$ \\
\hline $30-34$ & $7 / 7(100)$ & 2 & 0 & $176 / 392(45)$ \\
\hline $35-39$ & $5 / 6(83)$ & 0 & 1 & $105 / 342(31)$ \\
\hline $40-44$ & $3 / 5(60)$ & 0 & 0 & $79 / 336(24)$ \\
\hline $45-49$ & $4 / 5(80)$ & 0 & 0 & $61 / 335(18)$ \\
\hline $50-54$ & $1 / 3(33)$ & 1 & 0 & No data \\
\hline Total & $34 / 40(85)$ & $5^{*}$ & $2 \dagger$ & $1007 / 2248(45)$ \\
\hline
\end{tabular}

*Data missing for four women. †Data missing for three women.

\section{Results}

Forty women with cerebral sinus thrombosis who met the inclusion criteria were studied. The age related use of oral contraceptives in cases and controls and the prevalence of hereditary coagulation abnormalities in the cases are given in the table.

\section{Use of oral contraceptives}

Of the 40 cases, $34(85 \%)$ were using oral contraceptives at the time of the sinus thrombosis. In the control group 1007 of 2248 women (45\%) aged 18-49 years were using oral contraceptives. The age adjusted odds ratio for all ages (with the control data for the age group 45-49 also covering ages 50-54) was 13 (95\% confidence interval 5 to 37). The age adjusted odds ratio restricted to the ages $18-49$ was 18 ( 5 to 59 ).

\section{Coagulation abnormalities}

In 34 of the 40 women factor V Leiden mutation status was determined by DNA analysis and was present in four (12\%). Activated protein C resistance was measured in two women in whom no DNA was obtained, indicating the presence of the factor $\mathrm{V}$ Leiden mutation in one. Thus five of 36 women had factor V Leiden mutation (14\%; $5 \%$ to $30 \%)$. In the population the prevalence of factor $\mathrm{V}$ Leiden mutation is estimated to be $4-5 \%{ }^{13}$ Protein $\mathrm{C}, \mathrm{S}$, and antithrombin activity were assessed in 37 women; two $(5 \%)$ were deficient for protein $\mathrm{C}$.

Hence, a prothrombotic disorder was present in seven out of 36 patients with cerebral sinus thrombosis $(19 \% ; 8 \%$ to $36 \%)$. The estimated prevalence of protein $\mathrm{C}$ or $\mathrm{S}$ deficiency, or antithrombin deficiency, or of both, in the general population is $2-3 \% .^{14}{ }^{15}$ Thus, the prevalence of any hereditary prothrombotic disorder, including factor $\mathrm{V}$ Leiden, in the population is approximately $7 \%(6-8 \%)$. In carriers of hereditary prothrombotic conditions the odds ratio for developing sinus thrombosis is therefore 3.2.

Interaction between oral contraceptives and hereditary prothrombotic conditions - In the population the use of oral contraceptives and being a carrier of a hitherto unknown hereditary prothrombotic condition are probably independent, at least in women who have never had venous thrombosis. If the prevalence of hereditary prothrombotic conditions is $7 \%$ and $45 \%$ of women aged 15-49 in the population use oral contraceptives we may expect that $3 \%$ of women in the population both use contraceptives and carry a prothrombotic abnormality, $42 \%$ use contraceptives only, $4 \%$ carry the prothrombotic abnormality only, and $51 \%$ have neither risk factor. In the 36 patients for whom we had complete data these percentages were $17 \%, 72 \%$, $3 \%$, and $8 \%$, respectively. There is a clear excess of women with both risk factors in the patient series $(17 \%$ $v 3 \%$ ). If the estimated population percentages are used as reference the odds ratio for development of sinus thrombosis in women with both risk factors versus women with neither would be 34 . The odds ratios we found for the use of oral contraceptives (about 10) and for hereditary prothrombotic disorders (three to four) imply that oral contraceptives and being a carrier of a hereditary prothrombotic condition interact multiplicatively in their association with sinus thrombosis. 
Outcome of sinus thrombosis-Most patients recovered from their sinus thrombosis, but six (15\%) had a poor outcome after 3 months' follow up (four died, two were handicapped). Use of contraceptives was not associated with a worse outcome. Four of the 34 women (12\%) who used contraceptives had a poor outcome after 3 months (three died and one was disabled by a severe paralysis of her right arm and cognitive impairment) compared with two out of six women $(33 \%)$ not taking contraceptives.

\section{Discussion}

We have found an increased risk of cerebral venous sinus thrombosis in women who use oral contraceptives and are carriers of a hereditary prothrombotic disorder. In addition, we found that the use of contraceptives multiplies the risk of hereditary prothrombotic conditions.

\section{Sources of bias}

Before evaluating the clinical significance of our findings we must consider potential sources of bias. Because the cases were obtained in a treatment trial and the controls were a representative sample of the population, can the cases really be regarded as originating from the general population base? As all major neurological centres in the Netherlands, to which patients with sinus thrombosis are referred, participated in the trial the patients in the trial are representative of all patients with sinus thrombosis in the Netherlands. As there was no selection as to use of oral contraceptives or any other characteristic that might be related to use of contraception, the use of contraceptives in these patients can be validly compared with population data.

Pregnant women were excluded from the trial, and women in the puerperium or with a recent miscarriage were excluded from the analysis but not from the controls. Therefore oral contraceptive use in the controls might be slightly underestimated. The estimated percentage of premenopausal women who were pregnant or in the puerperium in the Netherlands was 5\% in $1994,{ }^{10}$ which is too small to affect our results.

As sinus thrombosis is a rare condition the chance that women with this disease were present in the control group is fairly small. According to the British registrar general the average mortality during the period 1952-61 from sinus thrombosis was $0.4 / 10^{6} /$ year. $^{16}$ If we assume a mortality of $10 \%$, the incidence would be $4 / 10^{6} /$ year.

Diagnostic suspicion and referral bias might occur if doctors were more likely to diagnose sinus thrombosis in women taking oral contraceptives. Women taking contraceptives might be under better medical supervision, and contraceptive use is known to increase the risk of venous thromboembolism. This type of bias has been suggested for deep vein thrombosis. ${ }^{17}$ For sinus thrombosis this bias seems unlikely. Sinus thrombosis is a rare and alarming disease, often with severe neurological symptoms. ${ }^{3}$ It seems reasonable to assume that all patients with sinus thrombosis are referred to a hospital, irrespective of oral contraceptive use. Misdiagnosis in our patients is unlikely because conventional angiography or magnetic resonance imaging, which are regarded as reliable diagnostic procedures for sinus thrombosis, ${ }^{18}$ were used in all cases.

\section{Known risk factors}

In various case series oral contraceptive use alone ${ }^{19}$ or superimposed on a hereditary prothrombotic disorder has been suggested as an aetiological factor for sinus thrombosis. A recent Italian case-control study in patients with sinus thrombosis found an odds ratio for oral contraceptive use of 4.2, after exclusion of pregnant and puerperal women. The presence of the factor V Leiden mutation in itself increased the risk for sinus thrombosis about ninefold..$^{20} 21$

Other probable risk factors for sinus thrombosis are pregnancy and puerperium. ${ }^{3}$ In our treatment trial seven women in the puerperium were included. Many other risk factors for sinus thrombosis have been reported in retrospective series, including the known risk factors for deep vein thrombosis, but a significant association with sinus thrombosis has not been demonstrated. The influence of smoking-if any-is unknown.

There is ample evidence that oral contraception predisposes to venous thromboembolism, ${ }^{17}$ especially when the factor $V$ Leiden mutation is present. ${ }^{2}$ The risk of leg vein thrombosis in women with the mutation who use oral contraceptives compared with women without the mutation who do not, increases more than 30 -fold. ${ }^{2}$ The tentative analysis of the interaction between oral contraceptive use and hereditary prothrombotic conditions in our study points in the same direction.

Recently, a biological explanation of the increased risk for venous thrombosis in oral contraceptives users was reported. ${ }^{22}$ In this study the effects of activated protein $\mathrm{C}$ on thrombin generation in the plasma of women using oral contraceptives were compared with the response in women not using oral contraceptives and in women heterozygotic or homozygotic for the factor V Leiden mutation. Oral contraceptives induced a degree of activated protein $\mathrm{C}$ resistance comparable with the resistance caused by a factor $\mathrm{V}$ Leiden mutation. In women heterozygotic for factor V Leiden mutation who used contraceptives the activated protein $\mathrm{C}$ resistance was as high as that among women homozygotic for the mutation. ${ }^{22}$ These results fit with the epidemiological data, including those from our series of patients with cerebral venous thrombosis, and are an additional argument against objections that the epidemiological findings are merely explained by prescription bias or other sources of confounding.

That sinus thrombosis is predominantly a disease of women was already clear from recent retrospective series. ${ }^{23}$ A comparison with sex distribution in larger series in the past, which showed no or a much less marked predominance of women in sinus thrombosis, ${ }^{24}$ suggests a shift in the epidemiology and aetiology of the disease in recent years. Possibly the widespread use of oral contraceptives has caused this increasing relative number of women with sinus thrombosis.

\section{Conclusion}

We conclude that the major risk factors for deep vein thrombosis and cerebral venous sinus thrombosis in women are the same. As the absolute risk for sinus thrombosis in premenopausal women is low, with an 
2 Vandenbroucke JP, Koster T, Briet E, Reitsma PH, Bertina RM, Rosendaal FR. Increased risk of venous thrombosis in oral-contraceptive users who are carriers of factor V Leiden mutation. Lancet 1994;344:1453-7.

- The use of oral contraceptives is associated with an increased risk of cerebral venous sinus thrombosis

- This risk of cerebral venous sinus thrombosis in women who use oral contraceptives is larger if there is an additional hereditary prothombotic factor (protein C, S, or antithrombin deficiency, factor V Leiden mutation)

- The association between oral contraceptives, thrombophilia, and deep vein thrombosis is also valid for cerebral sinus thrombosis

- Women do not need to stop using oral contraceptives as the absolute risk of cerebral sinus thrombosis is very small

estimated incidence of $4 / 10^{6} /$ year, our findings should not be used to advise against oral contraceptive use in all women. In women who have a history of venous thrombotic disease, including sinus thrombosis, however, advice against use of oral contraceptives should be considered, especially in women with a hereditary prothrombotic disorder.

The Cerebral Venous Sinus Thrombosis Study Group comprised S F T M de Bruijn, J Stam, A W A Lensing, J G P Tijssen, P M Bossuyt, LJ Kappelle, J Van Gijn, D WJ Dippel, P J Koudstaal, JJ Van Hilten, R A C Roos, J L A Eekhof, JJ Van der Sande, H L Hamburger, J Lodder, C C Tijssen, F W Bertelsman, JC Koetsier, P Sandercock, P Humphrey, G N Mallo, P Verlooy, H K Van Walbeek, J W Snoek, and C L Franke.

We thank $\mathrm{M}$ Budde for help in collecting patient data and blood samples; C Hooykaas, $\mathrm{H}$ van der Heide, and G C G Verweij for kindly providing control data; and M Vermeulen, H R Büller, and W A van Gool for their useful comments.

Contributors: SFTMdeB, JS, and JPV formulated the research hypothesis, designed the study, analysed the data, and wrote the paper. MMWK analysed the data on prothrombotic disorders and helped to write the paper. SFTMdeB collected and checked all data on use of contraceptives and prothombotic disorders, assisted by M Budde. SFTMdeB, JS, and JPV are guarantors for the paper.

Funding: The treatment trial was partly funded by Sanofi Winthrop.

Conflict of interest: None.

1 World Health Organization Collaborative Study of Cardiovascular Disease and Steroid Hormone Contraception. Venous thromboembolic disease and combined oral contraceptives: results of international multicentre case-control study. Lancet 1995;346:1575-82
3 Bousser M, Chiras J, Bories J, Castaigne P. Cerebral venous thrombosis: a review of 38 cases. Stroke 1985;16:199-213.

4 Deschiens MA, Conard J, Horellou MH, Ameri A, Preter M, Chedru F, et al. Coagulation studies, factor V Leiden, and anticardiolipin antibodies in 40 cases of cerebral venous thrombosis. Stroke 1996;27:1724-30.

5 Peters M, Breederveld C, Kahle LH, ten Cate JW. Rapid microanalysis of coagulation parameters by automated chromogenic substrate methods, application in neonatal patients. Thromb Res 1982;28:773-81.

6 Boyer C, Rothschild C, Wolf M, Amiral J, Meyer D, Larrieru M. A new method of estimation of protein C by ELISA. Thromb Res 1984;36: 579-89.

7 Deutz-Terlouw PP, Ballering L, Wijngaarden vA, Bertina RM. Two ELISAs for measurement of protein $\mathrm{S}$, and their use in the laboratory diagnosis of protein S deficiency. Clin Chim Acta 1989;186:321.

8 Dahlback B, Carlsson M, Svensson PJ. Familial thrombophilia due to a previously unrecognized mechanism characterized by poor anticoagulant response to activated protein C. Proc Natl Acad Sci USA 1993;90:1004-8

9 Voorberg J, Roelse J, Koopman R. Association of idiopathic venous thromboembolism with single point mutation at Arg 506 of factor V. Lancet 1994;343:1535-6.

10 CBS; Nederlands Instituut voor onderzoek van de Eerstelijnsgezondheidszorg; Inspectie voor de Gezondheidszorg. Enkele vormen van geboortenregeling. In: Centraal Bureau voor de Statistiek. Statistisch jaarboek 1996. The Hague: SDU, 1996:502.

11 Statistics Netherlands. Netherlands health interview survey 1981-1995. The Hague: SDU, 1996.

12 Rothman KJ. Modern epidemiology. Boston: Little, Brown, 1986.

13 Ridker PM, Miletich JP, Hennekkens CH, BuringJE. Ethnic distribution of factor V Leiden in 4047 men and women. Implications for venous thromboembolism screening. JAMA 1997;277:1305-7.

14 Hach-Wunderle V, Scharrer I. Pravalenz des hereditaren Mangels an Antithrombin III, Protein C und Protein S. Deutschen Medischen Wochenschrift 1993;118:187-90.

15 Tait RC, Walker ID, Reitsma PH, Islam SI, McCall F, Poort SR, et al. Prevalence of protein $\mathrm{C}$ deficiency in the healthy population. Thromb Haemost 1995;73:87-93.

16 Kalbag RM, Woolf AL. Cerebral venous thrombosis. London: Oxford University Press, 1967.

17 Realini JP, Goldzieher JW. Oral contraceptives and cardiovascular disease: a critique of the epidemiologic studies. Am J Obstet Gynecol 1985;152: 729-98.

18 Dormont D, Anxionnat C, Evrard S, Louaille C, Chiras J, Marsault C. MRI in cerebral venous thrombosis. J Neuroradiol 1994;21:81-99.

19 Buchanan LTCDS, Brazinsky MAJJH. Dural sinus and cerebral venous thrombosis incidence in young women receiving oral contraceptives. Arch Neurol 1970;22:440-4.

20 Martinelli I, Landi G, Merati G, Cella R, Tosetto A, Mannucci PM. Factor $\mathrm{V}$ gene mutation is a risk factor for cerebral venous thrombosis. Thromb Haemost 1996;75:393-4.

21 Martinelli I, Rosendaal FR, Vandenbroucke JP, Mannucci PM. Ora contraceptives are a risk factor for cerebral vein thrombosis [letter]. Thromb Haemost 1996;76:477-8.

22 Rosing J, Tans G, Nicolaes GA, Thomassen MC, van Oerle R, van der Ploeg PM, et al. Oral contraceptives and venous thrombosis: different sensitivities to activated protein $\mathrm{C}$ in women using second- and third generation oral contraceptives. Br J Haematol 1997;97:233-8.

23 Zuber M, Toulon P, Marnet L, Mas J. Factor V Leiden mutation in cerebral venous thrombosis. Stroke 1996;27:1721-3.

24 Krayenbühl HA. Cerebral venous and sinus thrombosis. Clin Neurosurg 1966;14:1-24.

(Accepted 11 November 1997)

\section{Fifty years ago}

\section{The new NHS: The press and the profession}

Speaking at the opening of the East Glamorgan County Hospital on Saturday, Mr. Aneurin Bevan, the Minister of Health, gave this advice to doctors: "Do not allow your minds to be inflamed or your judgment to be distorted by slogans which are addressed to your emotions and not to your intelligence." This sound piece of advice is perhaps hardly necessary for members of a profession used to making a differential diagnosis. The doctor uses the methods of science, and the politician the technique of the hustings. At this moment the medical profession is being subjected to abuse, misrepresentation, and malicious innuendo from the highly emotional press which supports Mr. Bevan. This campaign was started by the Tribune, of which Mr. Bevan was a director and editor until he took office in the present Government in 1945. The Tribune suggested that "the BMA may still try to fight the battle of the Tory Party against the development of a socialist service," and it went on to state: "Politically, the Minister's firmness has been most important. If he had been weak in face of this reactionary profession ... it would have increased doubts as to the intention to carry out a socialist programme."

(Editorial, 24 January 1948, p 155. See also editorial by Gordon Macpherson, 3 January 1998, p 6.) 